exist, varying in concept, recall period, and attribution ${ }^{1}$. As a consequence, the contribution of contextual factors may vary which has important implications when considering these factors in studies evaluating the impact of inflammatory arthritis (IA) and osteoarthritis (OA) on presenteeism.

Objectives: To determine demographic, job related and health related factors associated with three different global measures of presenteeism in patients with IA or OA.

Methods: This large cross-sectional international EULAR-PRO study ( $n=8$ countries) includes patients with RA, PsA, AS or OA in paid employment. Data collection included: demographics, job characteristics, health related and psychosocial factors. Patients also completed three global measures of presenteeism, varying in content, attribution and recall period. The Work Productivity Scale-Arthritis (WPS-A) measuring the affect of arthritis on productivity during the last 7 days, the Work Productivity and Activity Impairment Questionnaire (WPAI) measuring interference of arthritis on work productivity in the last month, and the Work Ability Index (WAI) a generic scale measuring current ability to work. For interpretation purposes the scale of the WAI was reversed in this study. Due to skewed data, univariable median regression analyses were performed to assess the association between independent variables with each individual presenteeism instrument. Results: 503 patients with IA/OA were recruited in this study with a mean age of 47 (SD10) yrs and disease duration of 12.6 (SD10) yrs. Except for male patients reporting a lower WPS-A score, no other demographics were significantly associated with presenteeism (table). Being neutral/unsatisfied about the job, not being able to organize one's own work, reporting higher VAS well-being and disability scores, and experiencing reduced quality of life were all significantly associated with higher presenteeism, a result observed for all three instruments. Furthermore, those with higher anxiety and depression scores also reported having more problems at work due to ill health. Discrepancies between instruments were especially observed between the WPAI (affect of ill health on productivity)/WPS-A (interference ills health on productivity) and WAI (generic scale on ability to work) in relation to job demands, receiving help from colleagues and the option to postpone work.

\begin{tabular}{|c|c|c|c|}
\hline & $\begin{array}{c}\text { WPAI } \\
\text { B(95\% CI) }\end{array}$ & $\begin{array}{l}\text { WPS-RA } \\
\text { B(95\%Cl) }\end{array}$ & $\begin{array}{c}\text { WAI } \\
\text { B(95\%Cl) }\end{array}$ \\
\hline \multicolumn{4}{|l|}{ Demographics: } \\
\hline $\begin{array}{l}\text { Age, years } \\
\text { Gender, female }\end{array}$ & $\begin{array}{l}0(-0.03,0.03) \\
0(-0.51,0.51)\end{array}$ & $\begin{array}{c}0(-0.03,0.03) \\
-1(-1.60,0.40)\end{array}$ & $\begin{array}{l}0(-0.02,0.02) \\
0(0.51,0.51)\end{array}$ \\
\hline \multicolumn{4}{|l|}{ Job characteristics: } \\
\hline $\begin{array}{l}\text { Job demands: } \\
\text { not/bit demanding } \\
\text { demanding } \\
\text { very demanding }\end{array}$ & $\begin{array}{c}1 \\
0(-0.72,0.72) \\
2(0.25,1.75)\end{array}$ & $\begin{array}{c}1 \\
1(0.12,1.88) \\
1(0.09,1.91)\end{array}$ & $\begin{array}{c}1 \\
0(-0.45,0.45) \\
0(-0.47,0.47)\end{array}$ \\
\hline $\begin{array}{l}\text { Job satisfaction: } \\
\text { very satisfied } \\
\text { neutral } \\
\text { unsatisfied }\end{array}$ & $\begin{array}{c}1 \\
1(0.03,1.97) \\
1(-0.08,2.08)\end{array}$ & $\begin{array}{c}1 \\
2(1.35,2.46) \\
2(1.28,2.72)\end{array}$ & $\begin{array}{c}1 \\
1(0.11,1.89) \\
1(0.00,2.00)\end{array}$ \\
\hline $\begin{array}{l}\text { Help colleagues: } \\
\text { often/always } \\
\text { sometimes } \\
\text { never }\end{array}$ & $\begin{array}{c}1 \\
0(0.49,0.49) \\
-1(-1.63,-0.37)\end{array}$ & $\begin{array}{c}1 \\
0(-0.75,0.75) \\
-1(-1.95,-0.05)\end{array}$ & $\begin{array}{c}1 \\
0(-0.49,0.49) \\
0(-0.63,0.63)\end{array}$ \\
\hline $\begin{array}{l}\text { Able to postpone tasks } \\
\text { often/always } \\
\text { sometimes } \\
\text { Never }\end{array}$ & $\begin{array}{c}1 \\
0(0.60,0.60) \\
1(0.30,1.70)\end{array}$ & $\begin{array}{c}1 \\
0(-0.60,0.60) \\
1(0.30,1.70)\end{array}$ & $\begin{array}{c}1 \\
0(-0.49,0.49) \\
0(-0.57,0.57)\end{array}$ \\
\hline $\begin{array}{l}\text { Able to organise work } \\
\text { often/always } \\
\text { sometimes } \\
\text { never }\end{array}$ & $\begin{array}{c}1 \\
1(015,1.85) \\
2(0.55,3.45)\end{array}$ & $\begin{array}{c}1 \\
0(-0.55,0.55) \\
1(0.06,1.94)\end{array}$ & $\begin{array}{c}1 \\
1(0.32,1.68) \\
1(-0.16,2.16)\end{array}$ \\
\hline \multicolumn{4}{|l|}{ PRO'S: } \\
\hline VAS well-being & $0.07(0.06,0.08)$ & $0.06(0.05,0.07)$ & $0.04(0.03,0.05)$ \\
\hline HAQ-score & $4(3.52,4.47)$ & $4(3.50,4.50)$ & $2.67(2.15,3.19)$ \\
\hline EQ-5D & $-6.50(-7.28,-5.71)$ & $-5.82(-6.67,-4.96)$ & $-3.22(-3.85,-2.58)$ \\
\hline HAD-Anxiety & $0.22(0.18,0.27)$ & $0.20(0.16,0.24)$ & $0.11(0.07,0.15)$ \\
\hline HAD-Depression & $0.31(0.24,0.39)$ & $0.33(0.27,0.39)$ & $0.27(0.22,0.33)$ \\
\hline
\end{tabular}

WPAI $(0=$ condition no effect on work $-10=$ condition completely prevented work): WPS-IA $/ O A(0=$ no interfer
$10=$ complete interference: WAI,$\langle 0=$ work ability at its best $-10=$ completely unable to work $)$ : PRO's=patient

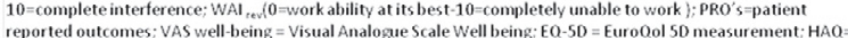
reported outcomes: $V A S$ well-being $=$ Visual $A$ analogue $S$ cale Well being: $E Q-S D=$ EuroOol $S D$ measurement: $\mathrm{HAQ}=$
health assessment questionnaire; $H A D=$ Hospital Anxiety and Depression scale. Bold values $=$ Statistically significant (p<0.05).

Conclusions: This is the first study investigating the association of many contextual factors with three commonly used global measures of presenteeism. Overall, job satisfaction and the ability to organize one's own work are the most important job characterises associated with presenteeism and should be considered when measuring presenteeism.

References:

[1] Ref. Leggett et al. Content validity of global measures for at-work productivity. Rheumatology, 2016;55:1364.

Acknowledgements: Funding: EULAR, AbbVie, BMS.

Disclosure of Interest: None declared

DOI: 10.1136/annrheumdis-2017-eular.5161

\section{FRI0723 TEMPORAL PATTERNS OF SEDENTARY BEHAVIOUR AND PHYSICAL ACTIVITY IN PATIENTS WITH RHEUMATOID ARTHRITIS}

S.A.M. Fenton ${ }^{1,2}$, J.L. Duda ${ }^{1}$, J.J. Veldhuijzen van Zanten $^{1,2}$, G.S. Metsios ${ }^{3}$, P.C. Rouse ${ }^{4}$, C.-A. Yu ${ }^{5}$, G.D. Kitas ${ }^{2} .{ }^{1}$ School of Sport Exercise and Rehabilitation Sciences, University of Birmingham, Birmingham; ${ }^{2}$ Rheumatology, Russells Hall Hospital, Dudley; ${ }^{3}$ Faculty of Education, Health and Wellbeing, Institute of Sport, Wolverhampton; ${ }^{4}$ Department for Health, University of Bath, Bath; ${ }^{5}$ School of Biomedical Sciences, University of Leeds, Leeds, United Kingdom

Background: Rheumatoid Arthritis (RA) is associated with increased risk of cardiovascular disease (CVD). Recent evidence suggests sedentary behaviour (waking behaviour $\leq 1.5$ metabolic equivalents whilst sitting/lying) may contribute towards the progression of RA outcomes, including heightened CVD risk (1). Sedentary behaviour occupies the majority of waking hours among people with RA (1). However, the proportion of time spent sedentary is likely to fluctuate over the course of the day, with periods of high sedentarity representing more optimal opportunity for intervention, and thus potentially higher intervention efficacy.

Objectives: The aims of this study were; 1) to explore temporal patterns of sedentary behaviour (and physical activity) among RA patients, and 2) to examine associations between temporal sedentary patterns and predicted 10-year risk of CVD.

Methods: Patients with RA ( $N=97)$ wore a GT3X accelerometer for 7 days to assess habitual sedentary time $(<100$ counts/min) and physical activity (PA; light $=100-2019$, moderate-to-vigorous $=\geq 2020$ counts $/ \mathrm{min})$. Accelerometer data were analysed separately for each hour (valid hour criteria; 60-minutes of data on $\geq 3$ days, including a weekend day). To evaluate 10-year risk of CVD (Q-risk2), patients reported their medical history, provided a fasted blood sample and underwent assessments of blood pressure and body-mass index.

Results: Temporal patterns of sedentary time and PA are reported in Figure 1. Sedentary time declined throughout the morning (08:00-12:00). During the afternoon, sedentary time increased by 4.5 minutes (12:00-18:00; $M$ $=34.36 \pm 8.86$ to $\mathrm{M}=39.06 \pm 7.91)$. A more marked increase in sedentary time was observed during leisure time (18:00-22:00; $M=39.61 \pm 7.59$ to $M=47.90 \pm 6.30$ ). Repeated measures analysis of variance (ANOVA) revealed sedentary time was significantly higher during leisure time ( $M=46.20 \pm 5.46)$ compared to the morning $(M=36.88 \pm 5.61)$, and afternoon $(M=38.50 \pm 6.07)[N=28, \quad F(2,26)=43.48$, $p=<0.01]$. Significant differences remained after accounting for employment status (i.e., employed vs. unemployed/student, $F(2,23)=1.40, p=0.27$ ). Patients who accumulated $M=>45.31$ sedentary minutes during their leisure time (18:00-23:00, median split), had significantly higher 10-year risk of CVD ( $M=22.23 \pm 13.83$ ) compared to those accruing $M=<45.31$ sedentary minutes $(\mathrm{M}=8.09 \pm 7.62)[\mathrm{t}(41)=3.92, p=<0.01]$. Finally, hourly patterns for light $\mathrm{PA}$ were the reverse of those observed for sedentary time. Hourly MVPA engagement was consistently $<3$ minutes (peak MVPA at 09:00-10:00, $M=2.47 \pm 4.16$ ).

Figure 1. Temporal patterns of sedentary time, light and moderate-to-vigorous physical activity

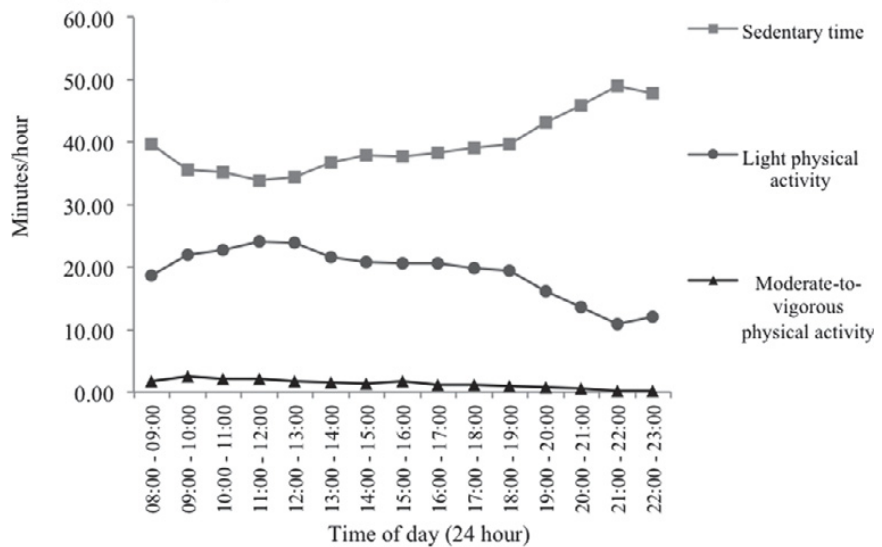

Note: Valid data available at each time point ranged from $\mathrm{N}=49(08: 00)$ to $\mathrm{N}=71$ (13:00). A total of $\mathrm{N}=41$ participants provided complete data across all hours during the morning $(08: 00-12: 00)$ and leisure time $(18: 00-23: 00)$. $\mathrm{N}=64$ participants complete data during the afternoon $(12: 00-18: 00)$.

Conclusions: Interventions targeting leisure time sedentary behaviour (18:0023:00), relative to more occupational sedentary behaviour (08:00-18:00), may offer the greatest potential for sedentary time reduction and associated improvements of CVD risk profile. Due to inverse patterns of engagement, replacing leisure time sedentary behaviour with light PA may offer an effective intervention approach.

References:

[1] Fenton SAM \& Kitas GD. Rheumatoid Arthritis: Sedentary behaviour in RA a new research agenda. Nat Rev Rheumatol 2016;12(12):698-700.

Disclosure of Interest: None declared

DOI: 10.1136/annrheumdis-2017-eular.590 